\title{
Die Theorie-Apotheke
}

Jochen Hörisch, der Professor für Literatur und Medienwissenschaft aus Mannheim, ist ein Meister der philosophischen Selbstdispensation. Sein Sortiment versteht er als eine «Handreichung zu den humanwissenschaftlichen Theorien der letzten fünfzig Jahre, einschliesslich ihrer Risiken und Nebenwirkungen». Unentbehrlich für alle, die mit heissem Herz und klarem Kopf mitdenken und verstehen wollen, für die, die nicht «gerne zeitlebens unmündig bleiben» und gemäss der berühmten Definition von Kant ihrer «selbstverschuldeten Unmündigkeit» entkommen wollen. Wer hat nebenberuflich genügend Zeit und Energie, alle Theorien von A bis Z, von «analytische Philosophie» über «Paradigmenwechsel» bis «Zivilisationstheorie», durchzulesen, $\mathrm{zu}$ verstehen und sie sich womöglich anzueignen? Zur Aufklärung gehört die Umstellung von Heils- auf Heilungserwartungen, ein Vorgang, den der Autor als «apothekarische Abkühlung aufgeheizter und fieberhafter Grosskonzepte» bezeichnet. Er weiss, dass alle Essenzen auch ein Verfalldatum haben, dass sie Arznei und Gift sein können, dass Medikamente auch mal das Problem und nicht die Lösung sind und dass keine Apotheke vollständig ist. Denken widersteht am längsten der «Furie des Verschwindens»: «Wer das Glück hat, mehrere Jahrzehnte lang komplexer Gedankengänge fähig zu sein, bleibt offenbar unter seinem Niveau, wenn er 1945, 1953, 1968, 1989 und nach dem 11. September 2001 dasselbe auf die dieselbe Weise mit denselben Leit-Begriffen denkt.» Diesem Mangel begegnet Jochen Hörisch mit seiner umfangreichen Rezeptur. Aus den vielen Arzneischubladen sei ein heute besonders aktuelles Präparat herausgegriffen:

\section{«Die Politische Theologie»}

Von den vielen Wahrheitsbegriffen hat die «martyriologische Wahrheitstheorie» ein gespenstisches Comeback erlebt. Ihr zufolge gilt: «wahr ist, wofür ich zu sterben bereit bin». Ausgehend von der amerikanischen Notrufnummer «nine/ eleven», kommentiert Jochen Hörisch die Wiederkehr der Polittheologie, die Wiederbelebung von Gotteskämpfern, denen das Reden von Satan und dem Reich des Bösen berufsmässig von den Lippen geht. Warum wir Schwierigkeiten haben, mit dieser Entwicklung umzugehen, liegt auch an einem Theoriedefizit, weil sich ein Polittheologe wie der Lehrer für Staatsrecht Carl Schmitt
(1888-1985) den Nazis angedient und damit nachhaltig diskreditiert hat. Was von diesen Schriften analytisch diskussionswürdig bleibt, ist die religiöse Fundierung des säkularen Staates. Daran erinnert die Präambel unserer Verfassung oder ein politischer Vorstoss der Rechten, der darauf abzielt, Abstimmungsentscheide, nach dem Motto «vox populi vox Dei» einer gerichtlichen Überprüfung zu entziehen. Dass die demokratische Alternative der Entkoppelung von Politik und Theologie immer wieder unterlaufen wird, belegen auch neuzeitliche Beispiele von Lenins Heiligenvita bis zu den Gebeten im «Oval Office». Niklas Luhmanns Aufsatz von 1986 über die «Grundwerte als Zivilreligion» beschreibt die religiöse Basis der Politsphäre, und die 2003 veröffentlichten Thesen des Ägyptologen Jan Assmann über «Die mosaische Unterscheidung oder der Preis des Monotheismus» belegen, was viele als Provokation empfinden. Alle monotheistischen Religionen sind von Haus aus intolerant: «Du sollst keine anderen Götter haben neben mir.» Das Gebot sorgt dafür, «dass erst ein monotheistischer Offenbarungsglaube für ultimative Eskalationen in Konfliktlogiken sorgt». Glaubensbekenntnisse sind keine Argumente, auch wenn es zunehmend mehr «satanischfrommen Köpfen tatsächlich um den rechten Glauben geht». Die Antwort lautet: vergleichende Religionswissenschaft statt politischer Theologie. Das Projekt der Moderne habe, wenn es gelingen wolle, nur eine Option offen, polytheistisch auf Weltbeheimatung zu setzen.

Für den Autor ist eine Aufwertung der Humanwissenschaften unumgänglich. Ein fragiles Prestige, weil es sich den systematischen Fehlleistungen von Menschen verdankt. Diese bilden eine erschreckend lange Mängelliste: «Die Probleme, die uns zu Beginn des dritten Jahrtausends erneut so irritierend zusetzen, sind geradezu beschämend anachronistische Probleme, zu deren Lösung Biogenetik, Neurophysiologie oder Astrophysik wenig beitragen: nämlich Probleme mit Gott, Fanatikern aller Art, Kulturen, die uns fremd bleiben, Konfliktlogiken, Verständigungsschwierigkeiten, Affektlagen, Fragen der Gerechtigkeit, des Geschlechterverhältnisses, des Mediengebrauchs, der Kindererziehung, der Technikfolgen und der Umweltzerstörung.»

Erhard Taverna
Frankfurt am Main: Eichborn Verlag, Die Andere Bibliothek; 2004; 322 Seiten. 